\title{
TENDÊNCIAS DAS PESQUISAS SOBRE INCLUSÃO NA EDUCAÇÃO SUPERIOR: CONTRIBUIÇÕES DA TEORIA HISTÓRICO-CULTURAL
}

\section{Tendencies of research on inclusion in Higher Education: contributions of the historical- cultural theory}

\author{
Tendencias de las investigaciones sobre inclusión en la Educación Superior: \\ contribuciones de la teoría histórico-cultural
}

Alexandra Ayach Anache ${ }^{1}$

Rosely dos Santos Madruga ${ }^{2}$

\begin{abstract}
Resumo
A inclusão na Educação Superior é um dos frutos da luta de pessoas marginalmente excluídas do processo educacional, especialmente considerando-se esse nível de ensino. Esse movimento resulta de anos de luta contra a discriminação do rótulo de incapacidade ante a sociedade segregadora e excludente. Este artigo se propõe a apresentar as contribuições das produções acadêmicas sobre a concepção de inclusão na Educação Superior. A metodologia de pesquisa é uma revisão sistemática da literatura, alicerçada na pesquisa bibliográfica integrativa. Os loci pesquisados foram os portais do Banco de Teses da Coordenação de Aperfeiçoamento de Pessoal de Nível Superior (Capes) e da Biblioteca Digital Brasileira de Teses e Dissertações (BDTD). Aplicamos o seguinte comando de busca: "teoria histórico-cultural" AND "educação superior" AND "inclusão" $O R$ "deficiência". O recorte temporal foram os anos 2007 - 2017. Os resultados, analisados com base na perspectiva histórico-cultural, indicam que a inclusão na Educação Superior é um desafio por ser um fenômeno recente no campo educacional e exige pesquisas e mudanças no âmbito da infraestrutura, do currículo, do sistema informativo e na formação do corpo docente e dos profissionais que atuam com os estudantes com deficiência.
\end{abstract}

PALAVRAS-CHAVE: Estudante com deficiência; Inclusão educacional; Educação

Superior; Teoria Histórico-Cultural.

ABSTRACT:Inclusion in Higher Education is one of the gains of the struggle of people marginally excluded from the educational process, especially considering this level of education. This movement results from years of struggle against discrimination on the label of disability before the segregating and excluding society. This article proposes to present the contributions of the academic productions on the conception of inclusion in Higher Education. The research methodology is a systematic review of the literature, based on integrative bibliographical research. The loci surveyed were the portals of the Banco de Teses da Coordenação de Aperfeiçoamento de Pessoal de Nível Superior (Capes), e da Biblioteca Digital Brasileira de Teses e Dissertações (BDTD). The loci searched were the portals of the Thesis Bank of the Coordination of Improvement of Higher Education Personnel (CAPES), and the Brazilian Digital Library of Theses and Dissertations (BDTD). We apply the following search command: "teoria histórico-cultural" AND "educação superior" AND "inclusão" OR "deficiência". The time cut was the years 2007 - 2017. "The results, analyzed based on

\footnotetext{
${ }^{1}$ Professora Titular da Faculdade de Ciências Humanas da Universidade Federal de Mato Grosso do Sul - UFMS. E-mail: <alexandra.anache@gmail.com>.

${ }^{2}$ Mestranda em Educação, no Programa de Pós-Graduação em Educação - UFMS. Técnica em Assuntos Educacionais, lotada na Pró-Reitoria de Assuntos Estudantis - Divisão de Acessibilidade e Ações Afirmativas UFMS. E-mail: <rstsmadruga@gmail.com>.
} 
historical cultural perspective, indicate that inclusion in Higher Education is a challenge because it is a recent phenomenon in the educational field and requires research and changes in the scope of infrastructure, curriculum, the information system and the training of faculty and professionals working with students with disabilities.

KEYWORDS: Student with disabilities; Educational inclusion; College Education; Cultural Historical Theory.

\section{Resumen}

La inclusión en la Educación Superior es uno de los frutos de la lucha de personas marginalmente excluidas del proceso educativo, especialmente considerando este nivel de enseñanza. Este movimiento resulta de años de lucha contra la discriminación de la etiqueta de incapacidad ante la sociedad segregadora y excluyente. Este artículo se propone a presentar las contribuciones de las producciones académicas sobre la concepción de inclusión en la Educación Superior. La metodología de investigación es una revisión sistemática de la literatura, basada en la investigación bibliográfica integrativa. Los loci investigados fueron los portales del Banco de Tesis de la Coordinación de Perfeccionamiento de Personal de Nivel Superior (Capes) y de la Biblioteca Digital Brasileña de Tesis y Disertaciones (BDTD). Aplicamos el siguiente comando de búsqueda: "teoría histórico-cultural" AND "educación superior" AND "inclusión" OR "deficiencia". Los resultados, analizados con base en la perspectiva histórico-cultural, indican que la inclusión en la Educación Superior es un desafío por ser un fenómeno reciente en el campo educativo y exige investigaciones y cambios en el ámbito de la infraestructura, del currículo, del sistema informativo y en la formación del cuerpo docente y de los profesionales que actúan con los estudiantes con discapacidad.

PALABRAS CLAVE: Estudiante con discapacidad; Inclusión educativa; Educación universitaria; Teoría Histórico-Cultural.

\section{INTRODUÇÃO}

O tema inclusão tem sido tratado por vários pesquisadores desde a década de $1990 \mathrm{em}$ contraponto à exclusão de parcelas da população que têm sido alijadas da educação, entre as quais se destacam os estudantes com deficiências, que neste artigo serão entendidos como pessoas “[...] que têm impedimentos de longo prazo, de natureza física, mental, intelectual ou sensorial, os quais, em interação com diversas barreiras, podem obstruir sua participação plena e efetiva na sociedade em igualdade de condições com as demais pessoas" (BRASIL, 2016, p. 14). Nos últimos anos, os debates sobre a inclusão dessas pessoas têm sido cada vez mais recorrentes (MOMBERGER, 2007; ANACHE, 2009; MOREIRA, 2012; MACIEL, ANACHE 2017).

Omote (2004) afirma que, após a Declaração de Salamanca, em 1989, o tema da inclusão foi difundido com o objetivo de contemplar vários grupos de pessoas excluídos da sociedade, entre os quais se destacam aqueles que apresentavam deficiências. Na oportunidade, houve críticas à educação formal em ambientes segregados e à perspectiva do déficit que embasava as ações e as relações no âmbito das escolas, pois os estudantes com essas 
características eram considerados pelas suas dificuldades, e não pelas suas possibilidades de aprendizagem e desenvolvimento. Obviamente, essa compreensão da deficiência gerou estigmas, estereótipos e preconceitos em vários níveis de ensino, inclusive na Educação Superior. Nesse sentido, “[...] o desvio e o estigma são construções sociais que cumprem a função de auxiliar no exercício do controle social. O controle social exercido pelo desvio e estigma implica a exclusão de pessoas assim marcadas" (OMOTE, 2004, p. 20).

Não são raros os estudos que abordam as condições experimentadas pelos estudantes com deficiências que obtêm acesso à educação superior. As pesquisas que realizamos sobre esse tema questionam o tipo de inclusão que os estudantes com deficiências experimentam nas instituições educacionais, sobretudo nas de educação superior. Martins (1997) afirma que parcelas da população historicamente marginalizadas se submetem a diferentes formas de inclusão marginal.

O processo de inclusão para o público-alvo da Educação Especial na Educação Superior favorece o acesso à aprendizagem e de forma igualitária aos demais estudantes? Mattos (2016, p. 23) informa que "[...] a inclusão das pessoas com deficiência deveria ser um processo inerente à sociedade, à medida que fosse desprezado o padrão de normalidade estabelecido, ao passo que se reconheceriam as diferenças funcionais enquanto singularidades do indivíduo". Ao refletirmos sobre esse fato, entendemos que o ato de exclusão antecede a inclusão, motivo pelo qual temos lutado para que esta ocorra em detrimento daquela. Ainda em Mattos (2016, p. 44), entendemos que no percurso histórico:

[...] a relação da sociedade com as pessoas com deficiência se constituiu de diferentes formas, em função do modo de conceber o fenômeno e, consequentemente, das práticas direcionadas a essa parcela da população ao longo do tempo. Entende-se que a formação do conceito de deficiência está atrelada ao cenário retratado a respeito da lógica econômica que respaldou a constituição das estruturas sociais, das forças produtivas e dos valores sociais e morais, bem como engendrou os processos de exclusão social de diferentes segmentos populacionais [...].

Na perspectiva de transformar a realidade dos estudantes com deficiência nos diversos níveis de ensino, têm-se criado leis, decretos e pareceres que, acompanhados da mobilização social, visam dar voz e vez ao estudante com deficiência, relevando sua identidade como um sujeito de direitos. A luta pela inclusão desses estudantes nas instituições de educação superior (IES) é um fenômeno recente nas pesquisas em Educação e exige maiores estudos em razão da complexidade das relações que envolvem a diversidade de estudantes e a universidade. Portanto, as ações que se anunciam como inclusivas fazem parte de um corpus social contraditório inserido na lógica de mercado. 
O conceito de deficiência foi produzido em meio aos movimentos sociais de lutas e estão em consonância com as exigências sociais. Nesse contexto, há concepções teóricas distintas, e as mais conhecidas são: metafísica, biológica e histórico-cultural (MATTOS, 2016).

$\mathrm{Na}$ abordagem metafísica, a deficiência foi entendida como castigo resultante de algum pecado. Portanto, as práticas mais comuns na estrutura social existente antes do cristianismo eram o infanticídio e o abandono. Na perspectiva biomédica, as causas da deficiência eram compreendidas como de natureza ambiental e biológica, enquanto no modelo social, o qual se aproxima da perspectiva histórico-cultural, entendeu-se que:

[...] deficiências são vistas, principalmente, através de lentes sociais, como uma série de respostas históricas, culturais e sociais à diferença humana. Em contraste ao modelo médico, que se concentra no indivíduo como sua unidade de análise [...] Em outras palavras, a forma como escolhemos responder às deficiências muda significativamente, dependendo se percebemos que "alguma coisa está errada com as pessoas com deficiência" ou se percebemos que "alguma coisa está errada com um sistema social que incapacita as pessoas" (VALLE; CONNOR, 2014, p. 13).

A deficiência foi considerada uma condição de atributos favoráveis ou desfavoráveis aos seres humanos constituídos nas relações sociais, ou seja, foi nesse contexto que os caracterizamos e atribuímos-lhes adjetivos como bom ou ruim e positivo ou negativo, conforme demonstraram os trabalhos que analisamos para este estudo.

\section{MÉTODO}

Com o objetivo de apresentar as contribuições da perspectiva histórico-cultural sobre a temática “inclusão na Educação Superior”, realizamos uma investigação bibliográfica de caráter exploratório em portais que divulgam os documentos científicos como teses e dissertações. Pesquisamos as produções disponíveis no Banco de Teses da Coordenação de Aperfeiçoamento de Pessoal de Nível Superior (Capes) na Biblioteca Digital Brasileira de Teses e Dissertações (BDTD). Utilizando suas plataformas, aplicamos o seguinte comando de busca: "teoria histórico-cultural” AND “educação superior” AND “inclusão" OR “deficiência”. O recorte temporal compreendeu o período de 2007 a 2017.

Recuperamos 48 documentos no período estipulado, dos quais foram examinados títulos, resumos, introdução e conclusão. Desse conjunto realizamos análise integrativa de conteúdos de 21 trabalhos (7 Teses e 14 dissertações) que atendiam aos objetivos desta pesquisa. Organizamos as análises das informações, considerando as características das produções, bem como seus fundamentos teórico-metodológicos, identificando as tendências das pesquisas sobre a inclusão na educação superior, com observância às contribuições da teoria 
histórico-cultural para promovê-la, uma vez que nessa perspectiva a educação é compreendida como processo de transformação da realidade social.

\section{RESULTADOS E DISCUSSÃO}

A análise dos 21 relatórios de pesquisa (14 dissertações e 7 teses) abordou os temas relacionados ao conceito de inclusão em diferentes abordagens teóricas, conforme demonstrado pelo Gráfico 1

Gráfico 1: Perspectivas teóricas

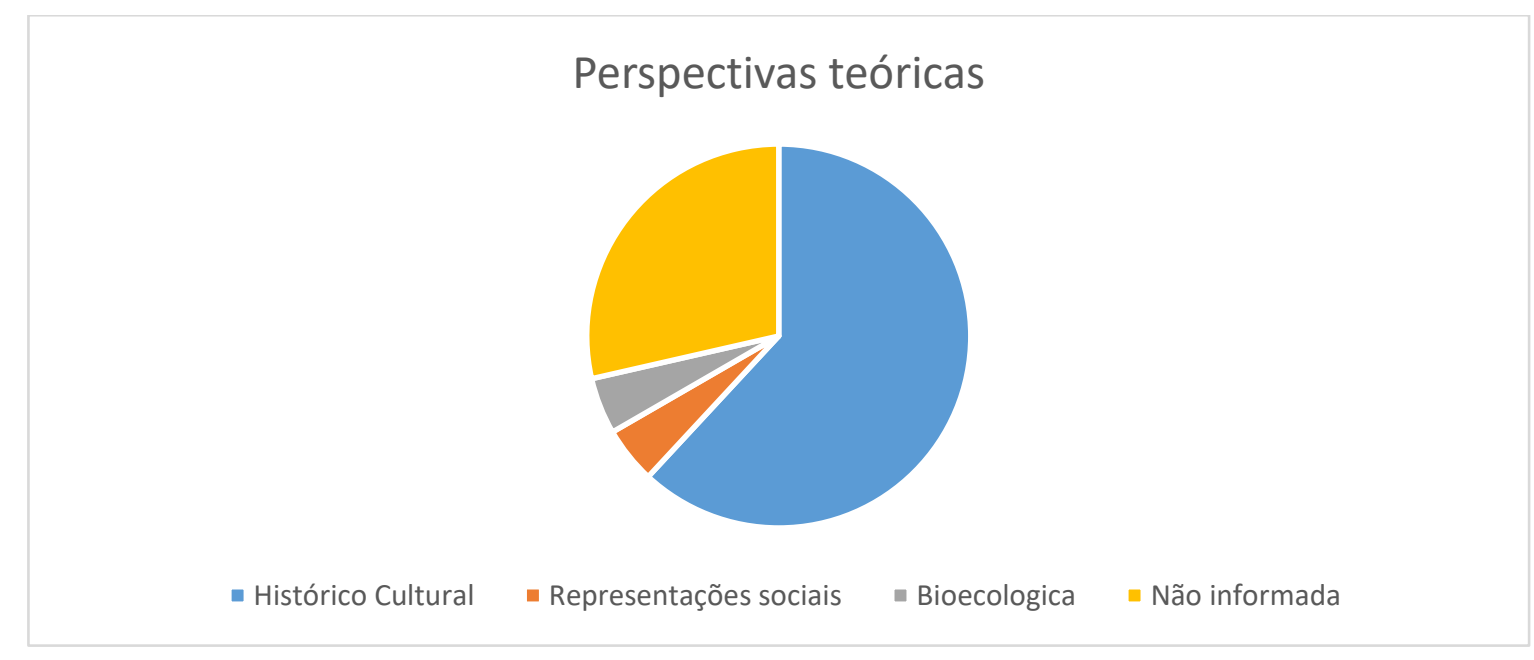

Fonte: Portal da Capes.

As publicações disponibilizadas indicam que oito relatórios foram redigidos nos programas de pós-graduação da Região Sul, cinco na Região Sudeste, quatro na Região Nordeste e quatro na Região Centro-Oeste. Esse fato demonstra que nas regiões Sul e Sudeste está concentrado o maior número de programas de pós-graduação na área de educação e áreas afins. Glat, Omote, Pletsch (2014) informaram que nos últimos anos houve aumento significativo de produções acadêmicas que depreenderam do crescimento de grupos e de linhas de pesquisas vinculados ou não aos cursos stricto sensu das universidades brasileiras. Nesse período, a área da educação especial e da educação de modo geral “[...] passou por diferentes concepções teóricas, modelos, filosofias e perspectivas, tanto como espaço de atuação profissional como campo de saber" (GLAT; OMOTE; PLETSCH, 2014, p. 26).

Os trabalhos relacionados sobre a inclusão na educação superior priorizaram os estudantes com deficiências físicas e sensoriais, coincidindo com os números das estatísticas oficiais que anunciaram ser este o público que tem tido acesso à educação superior, diga-se de passagem, desde o início do século passado, conforme informou Jannuzzi (2004). Os temas 
destacados pelas produções acadêmicas referiram-se às discussões sobre formação de professores e sobre as políticas de inclusão.

Os pesquisadores informaram que suas pesquisas são de natureza qualitativa, as quais podem ser caracterizadas como estudos descritivos e dois de caráter exploratórios. Quanto aos procedimentos de coleta de dados, foram identificadas as seguintes modalidades: (3) bibliográfica; (2) documental; (1) Survey; (1) pesquisa ação; (1) etnográfica; (1) história de vida; (2) estudo de caso; (2) pesquisa de campo. Os instrumentos de coleta de dados foram: (3) questionários; (9) entrevistas semiestruturadas; (6) análise documental; e (2) observação participante. Há estudos que utilizaram mais de um instrumento de pesquisa.

Diante do objetivo proposto neste estudo, analisamos treze trabalhos fundamentados na teoria histórico-cultural, dentre os quais destacamos os relatórios de pesquisa de Rambo (2010), Tavares (2014), Garcia (2015) e Michels (2016). De modo geral, a concepção de inclusão que eles abordaram refere-se à importância de todos os estudantes terem acesso a todos os níveis de ensino. Para tal, é necessário que as instituições viabilizem as condições para que os discentes consigam concluir seus cursos com êxito. Faé (2015), Agapito (2013), Santos (2012), Soares (2011) afirmaram que a inclusão é um paradigma que se pauta nos direitos humanos e, portanto, todos devem ter acesso à educação. Para que o processo de inclusão se efetive é necessário que se:

[...] valorizem, que respeitem as qualidades e potencialidades do ser humano, que sejam críticas e desenvolvam ações diárias, com práticas inclusivas de respeito e solidariedade. Que valorizem os resultados dos alunos, sejam eles quais forem, que não façam distinção entre alunos e seus resultados, que busquem colaboradores participativos, visando a atender às necessidades dos alunos com ou sem deficiência, contra rótulos e estigmas, a favor de uma sociedade mais justa (MICHELS, 2016, p. 120).

Os autores encontraram na perspectiva histórico-cultural fundamentos para desvelar os entraves que, aparentemente, foram apresentados como problemas do acadêmico e, como consequência, as adaptações são realizadas para atender às suas deficiências quando os investimentos devem ocorrer em todos os níveis visando superar as situações de fracasso escolar que a maioria dos estudantes vivenciou em seu percurso educacional (MICHELS, 2016). Nessa perspectiva, Agapito (2013) foi enfático em afirmar a necessidade de considerar o movimento da inclusão e exclusão no contexto da sociedade neoliberal, em que se corre o risco de um direito se transformar em mercadoria. Assim, no contexto da mercantilização, a invisibilidade das necessidades educacionais do estudante com deficiência, a sua diferença é obscurecida pela padronização de instrumentos e de tecnologias de ensino que em sua maioria foram organizadas na perspectiva da padronização de resultados esperados (MODOLON, 
2015). Aproximam-se dessa discussão os trabalhos de Rossetto (2010), Garcia (2015), Alcoba (2008) e Castro (2011).

Coutinho (2011) sugere que a concepção da relação entre diferença e deficiência na perspectiva da anormalidade precisará ser superada para viabilizar a construção de políticas efetivamente inclusivas. Nessa esteira, Sousa (2013) informa que, na UFES, a política educacional se aproxima da concepção de integração após o ingresso dos estudantes com deficiência pela via do vestibular, pois são eles que necessitam adaptar-se à realidade da IES, ou seja, às condições da instituição que se mantém a mesma, sem que houvesse investimentos tanto por parte do corpo docente quanto dos gestores para promover mudanças nas ações e relações institucionais. Sob essa compreensão, aprofunda-se a percepção de incapacidade por parte do acadêmico. Field's (2014) foi assertiva quando declarou que a inclusão se estabelece pela relação dialética, promovendo ações entrelaçadoras entre os estudantes e as instituições.

Os debates em torno da inclusão na educação superior ora vieram pela via do estudante para sinalizar as suas dificuldades em torno das condições de ensino que lhe são ofertadas, demonstrando, assim, os seus prejuízos acadêmicos, ora decorreram dos estudos das políticas de acesso e permanência, conforme foi apresentado por Monteiro (2014), Santos (2012), Jesus (2012), Fernandes (2012).

Para favorecer o sucesso acadêmico do estudante com deficiência, todos os trabalhos sinalizaram sobre a importância de investimentos na formação dos profissionais, conforme destacou Ribeiro (2011) ao afirmar que nem todos os docentes estavam preparados para trabalhar na perspectiva da inclusão. Do mesmo modo, na educação superior, é necessário que se avance com ações que contribuam para a construção de políticas de equidade em todas as esferas e para aqueles grupos que tiveram seus direitos vilipendiados. Lopes (2016) e Colacique (2013) asseveraram que é imprescindível que os currículos visem a formação integral do indivíduo, possibilitando-lhe a emancipação social, política e cultural.

Diante do exposto, concordamos com a afirmação de Fernandes (2012) sobre a sua compreensão de que trabalhar na perspectiva da inclusão é desafiador, conforme os argumentos que se seguem:

O desafio de incluir está posto. E esta realidade suscita novas conjunturas e implica aceitação das diferenças, superação de preconceitos e busca do devido preparo para lidar com essa nova realidade. E isso inclui nos prepararmos para propor a todos os educandos um conjunto de conhecimentos, tecnologias, recursos humanos e materiais didáticos que, em consonância com a abordagem da educação inclusiva, necessitará vincular nossas ações à qualidade da relação pedagógica entre os atores presentes nas escolas, e não apenas a um público-alvo delimitado, de modo que a atenção especial se faça presente para todos os que, em qualquer etapa ou modalidade da educação, dela necessitarem para o seu sucesso escolar (FERNANDES, 2012, p. 194). 
Silva Junior (2013) afirmou que a educação básica, ao oferecer os suportes necessários para os estudantes que participaram de sua pesquisa, favoreceu o seu ingresso na educação superior. No entanto, ao começar a frequentar os cursos universitários, tais estudantes enfrentaram dificuldades decorrentes de: infraestrutura precária, currículo inacessível, metodologias inadequadas, manifestações de atitudes preconceituosas e, sobretudo, reclamaram da falta de suporte necessário para darem prosseguimento aos seus estudos. A pesquisa de Rambo (2010, p. 11) asseverou que “[...] a inclusão significa ter maior acessibilidade e igualdade, e assim percebem que a educação inclusiva dentro das instituições de que fazem parte não está se concretizando”.

As pesquisas identificadas na perspectiva histórico-cultural demonstraram que a inclusão adquire sentidos diversos por ser um princípio desejado por uma sociedade de classes, em que a exclusão é sua característica basilar. Nesse contexto, a depender das condições sociais e econômicas dos estudantes com deficiência, o seu sucesso acadêmico poderá ser mais favorável, mas isso não os exime de experimentar situações de preconceito e discriminação. Portanto, é urgente que haja mudanças na cultura institucional por meio da construção de currículos que se estruturem na perspectiva da diferença, e não na normalização definidas por Rossetto (2010, p. 18) como “[...] normalização e homogeneização difundidas pela sociedade moderna". Em decorrência disso, as universidades como polos construtores e difusores de conhecimento deverão assumir seu papel de vanguarda para romper com as práticas educacionais excludentes. No entanto, da forma como tais instituições são ranqueadas pelas atuais políticas de avaliação dos seus órgãos de fomento, vislumbra-se um futuro de acirramento das desigualdades intramuros.

Todos os autores, dentre os quais se podem destacar Tavares (2014), Agapito (2013) e Silva Junior (2013), reafirmaram as contribuições da perspectiva histórico-cultural quando asseveraram que para favorecer os processos de aprendizagem devem-se conhecer as singularidades de cada pessoa e que as diferenças são constituídas na relação do sujeito com a sua cultura. Os principais conceitos destacados pelos autores é a relação entre deficiência primária e secundária, de compensação e, sobretudo, de zona de desenvolvimento eminente, tratada em alguns textos como zona de desenvolvimento proximal.

A zona de desenvolvimento proximal define aquelas funções que ainda não amadureceram, mas que estão em processo de maturação, funções que amadurecerão, mas que estão presentemente em estado embrionário. Essas funções poderiam ser chamadas de "brotos" ou "flores" do desenvolvimento, ao invés de "frutos" do desenvolvimento. O nível de desenvolvimento real caracteriza o desenvolvimento mental retrospectivamente, enquanto a zona de desenvolvimento 
proximal caracteriza o desenvolvimento mental prospectivamente (VYGOTSKY, 1997, p. 97 - grifo nosso).

Nesse sentido, o bom ensino favorece o desenvolvimento das neoformações psíquicas. Por isso, os autores são enfáticos na defesa de que a disponibilização de recursos necessários, como o uso de tecnologia assistiva, códigos linguísticos, Libras, entre outros, oferece suporte ao estudante com deficiência. Oliveira e Rodrigues (2011) reiteraram afirmando que as universidades devem investir na qualidade dos serviços oferecidos aos acadêmicos para que estes consigam concluir seus cursos com êxito.

Dentre os trabalhos mais destacados nos textos estudados temos os princípios do livro Fundamentos de defectologia ${ }^{3}$ de Vygotsky (1934/1997). Nessa obra, o autor sintetiza alguns trabalhos que escreveu com Luria e Leontiev. Eles estudaram o desenvolvimento atípico entre o final do século XIX e o início do século XX, propondo uma linha de investigação diferenciada para a época, pois agregavam conhecimentos advindos de outras áreas, dentre as quais se destacaram a psicologia, a medicina, a antropologia, a filosofia e a educação.

Na referida obra, o Vygotsky (1934/1997) retoma os estudos do fenômeno da compensação, que no período era concebido como capacidade natural que o ser humano tinha de construir outros caminhos para recompensar a ausência de um órgão, ou seja, o próprio organismo daria conta de exercer tal função. Contrapondo essa versão biológica, Vygotsky (1934/1997) afirmou que o peso da cultura e das condições concretas de vida do indivíduo exercia papel central no desenvolvimento das funções psicológicas superiores, recuperando a ideia de caminhos indiretos ou de vias colaterais.

Continuando nessa perspectiva, Vygotsky (1934/1997) defendeu a tese de que as funções cerebrais estão inter-relacionadas, são plásticas e podem se modificar em decorrência das condições educacionais e culturais disponibilizadas para o indivíduo com deficiência. Entre os seus argumentos, o autor citou como exemplo a história da norte-americana Hellen Keller, nascida em 1880, que era surda e cega e pôde superar as suas dificuldades por meio dos investimentos educacionais proporcionados por Anne Sullivan.

O desenvolvimento das funções psicológicas superiores decorre da apropriação dos signos, os quais foram considerados como recursos auxiliares que colaboram para a organização, o funcionamento do psiquismo e o domínio dos instrumentos disponíveis na sociedade, facilitando assim a participação social dos indivíduos.

\footnotetext{
${ }^{3} \mathrm{O}$ termo defectologia foi usado pelo autor em referência aos estudos sobre a deficiência na área da educação especial e não foi encontrada uma tradução correlata em português.
} 
Portanto, o precioso da obra é considerar que o valor atribuído à cultura no processo de desenvolvimento das funções psicológicas superiores é diferente tanto do ponto de vista genético quanto do estrutural das funções elementares e que elas depreendem da apropriação ${ }^{4}$ de conhecimentos, os quais se realizam em processos mediados. Nessa perspectiva, Prestes (2012) explicou que a colaboração de adultos ou pessoas mais capazes é imprescindível para que a aprendizagem devidamente planejada possibilite formas mais elevadas de conhecimento.

Portanto, todos os trabalhos analisados até aqui defendem a necessidade de maiores investimentos para oferecer condições de ensino, como infraestrutura apropriada, currículos adequados com metodologias ativas e colaborativas, formação em serviço e continuada para todos, incluindo os gestores, que são fundamentais para promover mudanças no processo educativo dos estudantes com deficiências em todos os níveis de ensino, devendo a Educação Superior assumir a posição de vanguarda nesse processo.

De modo geral, os trabalhos apontaram para a necessidade de construção de uma sociedade mais justa, colaborativa e, sobretudo, menos excludente. No entanto, advertiram que, em uma sociedade que se estrutura no movimento do capital, o conceito de inclusão adquire sentidos diferentes, a depender do contexto histórico em que ele é apresentado.

Assim, até 2014, aproximadamente, as produções acadêmicas estavam concentradas em estudar a ampliação do acesso à educação superior. Observou-se que as instituições particulares de capital privado possuíam a maior concentração de matrículas de estudantes com deficiências, se compararmos com as universidades públicas, em decorrência dos programas de financiamento do governo federal. Essa situação ocorreu sob a égide da expansão da educação superior.

A partir de 2015, a preocupação dos autores começa a se voltar para as condições de permanência e, consequentemente, indagou-se a respeito do tipo de inclusão que se oferecia aos estudantes com deficiências, ou seja, se as universidades estavam preparadas quanto à infraestrutura, à adequação do currículo, ao acesso às informações, e se possuíam corpos docente e técnico preparados. As respostas foram uníssonas no tocante à necessidade de transformação desse nível de ensino, rompendo as barreiras atitudinais e estruturais.

A partir da Lei Brasileira de Inclusão (2015) e, seguramente, após a implantação da Lei de Cotas para estudantes com deficiências (2016), o tema inclusão tem marcado presença nos bancos de teses e dissertações das universidades, ampliando a sua incursão para as políticas universitárias mediante o programa de expansão da educação superior do governo federal, o

\footnotetext{
${ }^{4}$ Termo descrito na obra Fundamentos de defectologia.
} 
qual se estrutura em meio ao sucateamento desse nível de ensino. Esse é um diálogo promissor que deverá reservar novas investiduras.

\section{CONSIDERAÇÕES FINAIS}

Ao apresentar as contribuições das produções acadêmicas sobre a tendência das produções que pesquisaram a inclusão na Educação Superior, pode-se concluir que há necessidade de maiores investimentos para que os Planos de Desenvolvimentos Institucionais se fundamentem nos princípios da educação inclusiva, assegurando que os desenhos curriculares promovam transformações da cultura desses espaços em todos os níveis de ensino.

Os relatórios de pesquisa demonstraram que ocorreram avanços no acesso de estudantes com deficiências à Educação Superior, requerendo, com isso, ações que promovam condições para que os estudantes com deficiências consigam concluir seus cursos. Para isso, é importante que aconteçam mudanças substanciais na organização da proposta pedagógica dos cursos em suas diferentes modalidades e níveis, os quais extrapolam a função dos núcleos de acessibilidade ou órgão correlatos. Certamente, isso exigirá o esforço para que os profissionais (docentes e técnicos administrativos) sejam orientados tanto em sua formação inicial como na continuada para dar sustentação a essas proposituras.

Portanto, novas pesquisas sobre a diferenciação curricular precisam ser desenvolvidas para promover mudanças nas metodologias, nos processos avaliativos, na produção de recursos de tecnologia assistiva e de informação, prevendo ainda o investimento em contratação e formação de Tradutores Intérpretes de Língua Brasileira de Sinais, em Profissionais Especialistas em Audiodescrição e em Braile, entre outros, que possam favorecer a formação dos acadêmicos com deficiências. Nessa esteira, é essencial o aprofundamento de estudos sobre a terminalidade específica nesse nível de ensino, o qual foi silenciado pelas políticas atuais.

Em que pesem os avanços da Política Nacional de Educação Especial na perspectiva da Educação Inclusiva em garantir o acesso e a permanência de estudantes com deficiência nesse nível de ensino, o sucesso acadêmico ainda se deve exclusivamente ao esforço próprio e de seus familiares, reafirmando assim a cultura da competência individual, característica do modelo neoliberal.

\section{REFERÊNCIAS}

ALCOBA, S. de A.C. Estranhos no ninho: a inclusão de alunos com deficiência na Unicamp. Tese (Doutorado em Educação) - Faculdade de Educação. Universidade Estadual de Campinas (UNICAMP), Campinas, SP, Brasil, 2008 
AGAPITO, Juliano. A formação inicial de professores na perspectiva da educação inclusiva: um olhar para a diversidade. 2013. 195 f. Dissertação (Mestrado em Educação) - Universidade da Região de Joinville, Joinville.

ANACHE, Alexandra Ayach. A epistemologia qualitativa: contribuições para a pesquisa em educação especial. Revista Intermeio, v. 15 n. 30, 2009.

BRASIL, Censo Escolar Da Educação Básica. 2016: Caderno de Instruções. Brasília. 2016. Disponível em: <http://download.inep.gov.br/educacao_basica/educacenso/matricula_inicial/2016/documento s/caderno_de_instrucoes_2016.pdf>. Acesso em: 21 out. 2017.

COLACIQUE, Rachel. Acessibilidade para surdos na cibercultura: os cotidianos nas redes e na educação superior online. 2013. 164 f. Dissertação (Mestrado em Educação) - Universidade do Estado do Rio de Janeiro, Rio de Janeiro.

COUTINHO, Marcia Maria de Azeredo. A inclusão da pessoa com deficiência visual na Educação Superior e a construção de suas identidades. 2011. 104 f. Dissertação (Mestrado em Educação) - Universidade Católica Dom Bosco, Campo Grande.

FAÉ, Monick Barbosa Ribeiro. Acesso à Educação Superior: o ponto de vista dos alunos do Ensino Médio com necessidades educacionais especiais. 2015. 91 f. Dissertação (Mestrado em Educação) - Universidade Federal do Espírito Santo, Vitória.

FERNANDES, Sandra de Freitas Paniago. A formação de professores de ciências biológicas e a educação inclusiva: uma interface da formação inicial e continuada. 2012.198 f. Dissertação (Mestrado em Educação em Ciências e Matemática) - Universidade Federal de Goiás, Goiânia.

FIELD'S, Karla Amâncio Pinto. Saberes profissionais para o exercício da docência em química voltado para a educação inclusiva. 2014. 195 f. Tese (Doutorado em Química). Universidade Federal de Goiás, Goiânia.

GARCIA, Dorcely Isabel Bellanda. Política Nacional de Educação Especial na perspectiva da educação inclusiva na Região Sul do Brasil. 2015. 275 f. Tese (Doutorado em Educação) Universidade Estadual de Maringá, Maringá.

GLAT, Rosana; OMOTE, Sadão; PLETSCH, Márcia Denise. Análise das contingências da produção do conhecimento em educação especial. In: OMOTE, Sadão; OLIVEIRA, Anna Augusta Sampaio de; CHACON, Miguel, Claudio Moriel. Ciência e conhecimento em educação especial. São Carlos: Marquezine \& Manzini ABPEE, 2014. p. 25-44.

JANNUZZI, Gilberta de Martino. A educação do deficiente no Brasil: dos primórdios ao início do século XXI. Campinas: Autores Associados, 2004.

JESUS, Ivone das Dores de. Analisando a educação inclusiva no curso de Licenciatura em Geografia da Universidade Estadual do Maranhão. 2012. 98 f. Dissertação (Mestrado em Educação) - Universidade Federal do Maranhão, São Luís. 
LOPES, Betania Jacob Stange. Programa de transição para a vida adulta de jovens com deficiência intelectual em ambiente universitário. 2016. 243 p. Tese (Doutorado em Educação) - Universidade Federal de São Carlos - UFSCar, 2016.

MACIEL, Carina Elisabeth; ANACHE, Alexandra Ayach. A permanência de estudantes com deficiência nas universidades brasileiras. Educar em Revista, [S.1.], p. 71-86, dez. 2017. Disponível em:<http://revistas.ufpr.br/educar/article/view/52924/34098>. Acesso em: 5 mar. 2018.

MARTINS, José de Souza. Exclusão social e a nova desigualdade. São Paulo: Paulus, 1997. v. 2.

MATTOS, Beatriz Marques. Deficiência: da conceituação aos posicionamentos de universitários. 2016. 106 f. Dissertação (Mestrado em Psicologia do Desenvolvimento e da Aprendizagem) - Universidade Estadual Paulista, Faculdade de Ciências, Bauru.

MICHELS, Julia Graziela Della Justina. A política de educação inclusiva nas instituições de educação superior da região sul de Santa Catarina. 2016. 2016136 f. Dissertação (Mestrado em Educação) - Universidade do Sul de Santa Catarina, Tubarão.

MODOLON, Joice Rodrigues. Diversidade socioeconômica e educação inclusiva: um estudo de caso na Faculdade de Tecnologia Senac Tubarão - Santa Catarina. 2015. 136 f. Dissertação (Mestrado em Educação) - Universidade do Sul de Santa Catarina, Tubarão, Tubarão.

MOMBERGER, M. M. Inclusão no ensino superior: itinerários de vida de acadêmicos com necessidades educacionais especiais. 2007. 136 f. Dissertação (Mestrado em Educação) Programa de Pós-Graduação em Educação, Universidade Federal do Rio Grande do Sul, Porto Alegre.

MONTEIRO, Aline Hygino Carvalho. Inclusão de alunos com necessidades educacionais específicas no IFRJ - Campus Volta Redonda: um estudo de caso das licenciaturas em Física e em Matemática. Brasil. 2014199 f. Dissertação (Mestrado em Educação, Contextos Contemporâneos e Demandas Populares) - Universidade Federal Rural do Rio de Janeiro, Seropédica.

MOREIRA, Laura Cereta. Políticas inclusivas no ensino superior: da implantação à concretização. Dimensões pedagógicas nas práticas de inclusão escolar. Marília: ABPEE, 2012. p. 97-108.

OLIVEIRA, Marinalva Silva; RODRIGUES, Lidiane Furtado Ferreira. A inclusão no ensino superior: uma experiência em debate. PRACS: Revista Eletrônica de Humanidades do Curso de Ciências Sociais da Unifap, v. 4, n. 4, p. 17-28, 2011.

OMOTE, Sadão et al. Mudança de atitudes sociais em relação à inclusão. Paidéia, Ribeirão Preto, Ribeirão Preto, v. 15, n. 32, p. 387-396, dez. 2004. Disponível em: $<$ http://www.scielo.br/scielo.php?script=sci_arttext\&pid=S0103863X2005000300008\&lng=p t\&nrm=iso $>$. Acesso em: 7 ago. 2017. 
PRESTES, Zoia Ribeiro. Quando não é a mesma coisa: análise de traduções de Lev Semionovitch Vygotsky no Brasil: repercussões no campo educacional. 2012. 295 f. Tese (Doutorado em Educação) - Universidade de Brasília, Brasília.

RAMBO, Carla Patrícia. A inclusão escolar na perspectiva de alunos com deficiência no ensino superior: contribuições da psicologia histórico-cultural. 2010. 152 f. Dissertação (Mestrado em Psicologia) - Universidade Estadual de Maringá, Maringá.

RIBEIRO, Eveline Borges Vilela. Formação de professores de ciências e educação inclusiva em uma instituição de ensino superior em Jataí-GO. 2011. 107 f. Dissertação (Mestrado em Educação) - Universidade Federal de Goiás, Goiânia.

ROSSETTO, Elisabeth. Sujeitos com deficiência no ensino superior: vozes e significados. 2010. 234 f. Tese (Doutorado em Educação) - Universidade Federal do Rio Grande do Sul, Porto Alegre.

SANTOS, Andreza Souza. Inclusão de estudantes com deficiência nas instituições de ensino superior da cidade do Natal/RN: análise das condições oferecidas no processo seletivo vestibular. 2012. Dissertação (Mestrado em Educação) - Universidade Federal do Rio Grande do Norte, Natal.

SILVA JUNIOR, Bento Selau da. Fatores associados à conclusão da educação superior por cegos: um estudo a partir de L. S. Vygotsky. 2013. 287 f. Tese (Doutorado em Educação) Universidade Federal de Pelotas, Capão do Leão.

SOARES, Ana Cristina Silva. A inclusão de alunos com deficiência visual na Universidade Federal do Ceará: ingresso e permanência na ótica dos alunos, docentes e administradores. 2011. 240 f. Tese (Doutorado) - Pós-graduação em Educação Brasileira. Universidade Federal do Ceará, Fortaleza.

SOUSA, Haila Lopes de. Para lembrar que você existe: um estudo de caso sobre as políticas de inclusão para os estudantes com deficiência na Universidade Federal do Espírito Santo. 2013. 150 f. Dissertação (Mestrado em Educação) - Universidade Federal do Espírito Santo, Vitória.

TAVARES, Ana Paula da Paz. Educação especial no ensino superior: acessibilidade no processo de inclusão escolar, a partir de relatos de acadêmicos com deficiência. 2014. $147 \mathrm{f}$. Dissertação (Mestrado em Psicologia) - Universidade Estadual de Maringá, Maringá.

VALLE, J. W.; CONNOR, D. J. Ressignificando a deficiência: da abordagem social às práticas inclusivas na escola. Tradução de Fernando de Siqueira Rodrigues. Porto Alegre: AMGH, 2014.

VYGOTSKY, L. S. Fundamentos da defectologia. Madrid: Visor, 1997. (Obras escogidas, t. V.)

Manuscrito de 1929. Educação \& Sociedade, v. 21, n. 71, p. 21-44, 2000. 
ISSN 2237-258X

Recebido em:28/10/2017

Aprovado em:04/01/2018 